\title{
Late initiation of antenatal care and associated factors among pregnant women in Addis Zemen primary hospital, South Gondar, Ethiopia
}

\author{
Haileab Fekadu Wolde ${ }^{*}$, Adino Tesfahun Tsegaye and Malede Mequanent Sisay
}

\begin{abstract}
Background: Antenatal care (ANC) is special care for pregnant women with the aim of preventing, detecting and treating health problems in both the fetus and mother. Early ANC attendance promotes early detection and treatment of complications which result in proper management during delivery and puerperium. However, the majority of pregnant women in Ethiopia initiate their ANC late. Therefore, this study aimed to assess the prevalence of late initiation of ANC and its associated factors among attendants in Addis Zemen primary hospital.

Method: An institution-based cross-sectional study was conducted at Addis Zemen primary hospital from February 7 to June 122,018. The systematic random sampling technique was employed to select 369 pregnant women who attended ANC in the hospital. Data cleaning and analysis was done using SPSS version 25 statistical software. Descriptive statics and bi variable and multivariable logistic regression models were employed to assess the magnitude and factors associated with late initiation of ANC defined as making the first visit after 12 weeks of gestation.

Result: This study indicated that $52.5 \%$ of the attendants initiated ANC late. The multivariable logistic regression analysis showed that being housewife (Adjusted odds ratio $(A O R)=2.85,95 \%$ Cl: 1.36, 5.96), self-employment ( $\mathrm{AOR}=2.38,95 \% \mathrm{Cl}$ : 1.12, 5.04), travel expenses (AOR $=1.72,95 \% \mathrm{Cl}: 1.05,2.81)$, poor knowledge about $\mathrm{ANC}(\mathrm{AOR}=2.98,95 \% \mathrm{Cl}: 1.78,5.01)$ and unplanned pregnancy $(\mathrm{AOR}=2.31,95 \% \mathrm{Cl}: 1.28,4.16)$ were significantly associated with late ANC initiation.

Conclusion: The prevalence of late ANC initiation remains a major public health issue in Ethiopia. The major factors for being late were found to be poor knowledge, being housewife, and self-employment, travel expenses and unintended pregnancy. District and zonal health offices should work to create awareness about the importance of early initiation of ANC, make the service closer to the community and increase contraceptive utilization.
\end{abstract}

Keywords: Antenatal care, Late initiation, Pregnant women, Risk factors

\section{Plain English summery}

Antenatal care is a special care that is provided for pregnant women with the aim of improving the health of the unborn baby and the mother. According to WHO recommendation, every pregnant women should book ANC before 12 weeks of gestation. Early initiation of ANC has the benefit of early detection and treatment of complications during pregnancy. However, the majority of women

\footnotetext{
* Correspondence: haileabfekadu@gmail.com

Department of Epidemiology and Biostatistics, Institute of Public Health College of Medicine and Health Sciences, University of Gondar, Gondar Ethiopia
}

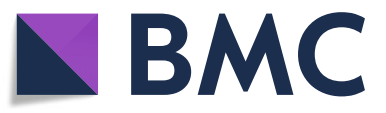

(c) The Author(s). 2019 Open Access This article is distributed under the terms of the Creative Commons Attribution 4.0 International License (http://creativecommons.org/licenses/by/4.0/), which permits unrestricted use, distribution, and reproduction in any medium, provided you give appropriate credit to the original author(s) and the source, provide a link to the Creative Commons license, and indicate if changes were made. The Creative Commons Public Domain Dedication waiver (http://creativecommons.org/publicdomain/zero/1.0/) applies to the data made available in this article, unless otherwise stated.

in Ethiopia initiate ANC late. Therefore, the objective of this study was to assess the magnitude of late initiation of ANC and factors affecting it among ANC attendants in Addis Zemen primary hospital.

Of the total 364 participants, 191 started their follow up late. Being housewife, self employment, travel cost, poor knowledge about ANC and unintended pregnancy were the factors that increased the likelihood of initiating ANC late.

In conclusion, late initiation of ANC was high in the study area. Poor knowledge level, being housewife and selfemployment, travel expenses and unintended pregnancy 
were significantly associated with late initiation of ANC. creating about the importance of early initiation of ANC, making the service closer to the community and increasing contraceptive utilization would help to decrease the number of mothers who start ANC late.

\section{Background}

Maternal mortality reduction remains a priority agenda in the new sustainable development goals (SDGs 3). However, it remains the global challenge with 275,288 deaths due to pregnancy and related complications in 2015 [1]. The burden is high in developing countries, accounting for $99 \%$ of the global maternal deaths in 2015, with the Sub-saharan Africa region including Ethiopia contributing $66 \%$ of the mortality $[2,3]$. Most of the causes of maternal deaths are preventable, detectable, and treatable. Therefore, immediate action is needed to meet the ambitions of SDG 2030 for eliminating preventable causes of maternal death with a special attention to Sub- saharan Africa $[4,5]$ Antenatal care is one of the key strategies for reducing maternal and neonatal morbidity and mortality directly through the detection and treatment of pregnancy related illness, or indirectly through detection of women at risk of complications of delivery and ensuring that they deliver in a suitably equipped facility. During ANC, health providers monitor and identify risk factors related to poor maternal and birth outcomes. Once problems are identified, providers can initiate appropriate medical and educational interventions to reduce the risks for maternal-neonatal morbidity and mortality $[6,7]$. However, early ANC visit is very low (24\%) in low income countries compared with $81.9 \%$ in developed countries [8].

ANC services, especially the first visit, includes essential screening for health conditions such as human immunodeficiency virus (HIV) and Syphilis; for HIVinfected pregnant women, the maximum benefit of antiretroviral therapy (ART) to prevent mother-to-child transmission (PMTCT) of HIV requires early presentation to the health system. Screening for syphilis should be offered to all pregnant women at an early stage of ANC because treatment of syphilis is beneficial to the mother and the fetus. In pregnant women with early untreated syphilis, 70 to $100 \%$ of the infants will be infected and one-third will be stillborn. Furthermore, iron supplementation and immunizations, such as Tetanus Toxoid (TT), given during pregnancy can be life-saving for both mothers and infants if it is initiated at an early stage of pregnancy [9-12]. Early initiation of ANC also has a big role in reducing bad perinatal outcomes like preterm birth, low birth weight [13], and jaundice [14]. The aims of early ANC booking are identification of complications or risk factors for complications which enable early interventions to alleviate or mitigate the effects of such complications on mothers and unborn babies [15].

Since 2003, the Ethiopian government has been deploying specially trained new cadres of communitybased workers called Health Extension Workers (HEWs) . HEWs are expected to spend $75 \%$ of their time in outreach activities by going from house to house in their respective kebeles. They are trained on how to provide care to pregnant women throughout pregnancy, birth and post natal period [16].

Factors identified for late initiation of ANC include lack of education, poor knowledge about ANC, unplanned pregnancy, high cost ofANC, low income, multi parity, unemploymentand having history of abortion, [10, 17-23].

Even though WHO (World Health Organization) recommends that the first ANC visit be within the first 12 weeks of pregnancy [7], studies conducted in different parts of Ethiopia showed very low coverage, and that most of the women who started their follow up late [24-27]. In order to decrease child and maternal mortality, it is crucial to know the time of the first ANC visit of pregnant women and factors affecting it. Therefore, this study aimed to measure the magnitude and factors associated with late initiation of ANC at Addis Zemen primary hospital.

\section{Methods}

\section{Study design and setting}

An institution based cross-sectional study was conducted from February 7 to June 12, 2018.The study was conducted atAddis Zemen primary hospital, located in Libo kemkem district South Gondar, Amhara regional state, $658 \mathrm{KM}$ northwest of Addis Ababa. The district had an estimated population of 198, 951 of whom 100, 951 were male and 97,423 female [28]. Addis Zemen town had 28,003 male and 28,913 are female inhabitants. The town and its suburbs, have a primary hospital, a health center and 8 health posts. The hospital has opened2016, provides general care in medical, surgical, gynecology or obstetrics and pediatrics wards (Fig. 1).

\section{Study population and sampling procedure}

The study populations of this study were all pregnant mothers who visited Addis Zemen primary hospital during the study period. Mothers mentally and physically incapable of being interviewed were excluded. The sample size was determined by using the formula for the estimation of a single population proportion with an assumption of $95 \%$ confidence interval, $5 \%$ margin of error, and $64.6 \%$ of expected proportion of late booking for ANC [11]. To compensate for the non-response rate, $10 \%$ of the determined sample size was added. A sample of 364 pregnant women who were attending ANC Clinic were selected using systematic random sampling technique with a skip 


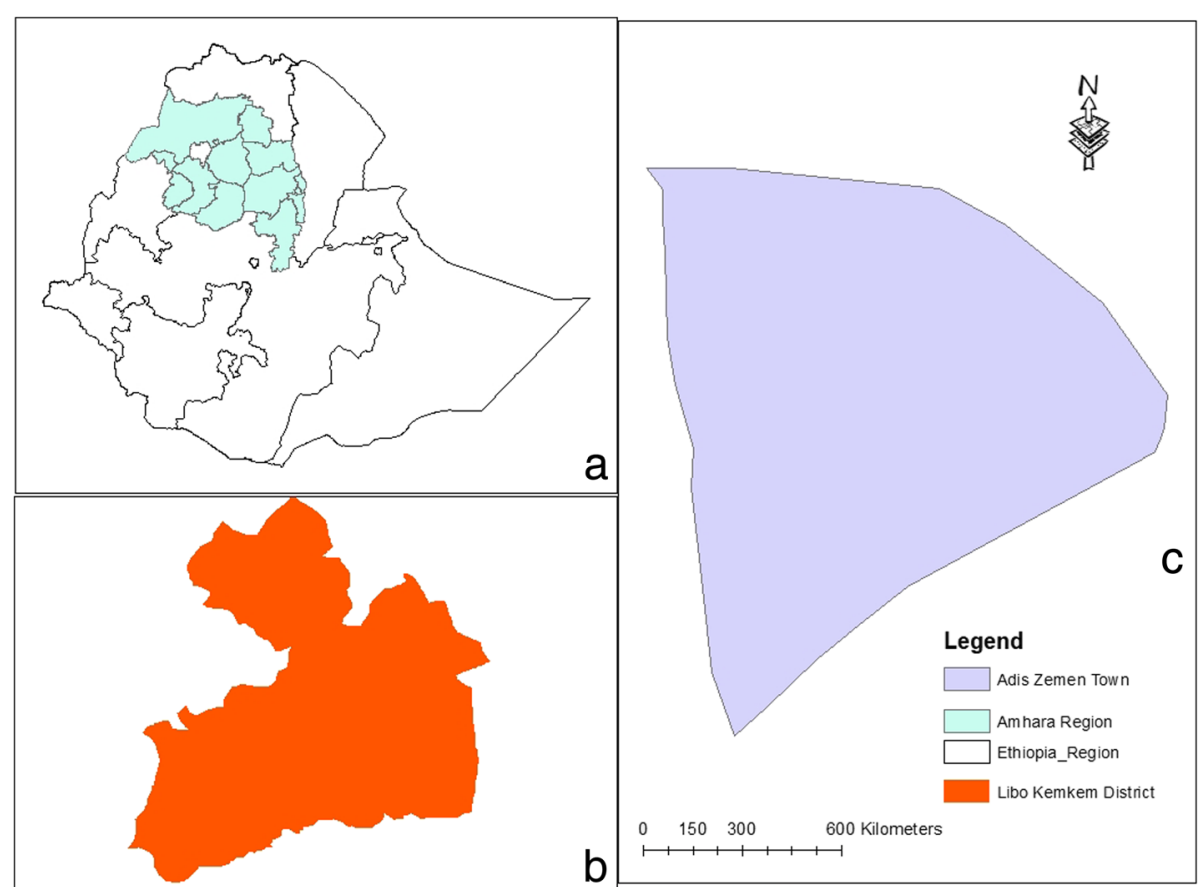

Fig. 1 Location of the study area. a Ethiopia. b Libo-Kemkem. c Addis Zemen

interval of 2 was used, and the first subject was selected by using the lottery method.

\section{Variables data collection procedures}

The outcome variable of the study was late booking for ANC which was defined as booking ANC after 12 weeks of gestation [12]. The explanatory variables included sociodemographic factors (age, religion, ethnicity, marital status, educational level, monthly income, occupation and travel cost); obstetric factors (gravidity, parity, history of abortion, type of pregnancy, history of ANC, timing of the first ANC visit from previous pregnancy, history of cesarean section (CS), history of still birth, problem in the last pregnancy and history of child death); enabling factors (distance from health institution, cost of travel), and need factor which includes knowledge towards ANC. Knowledge was measured using nine questions with "yes"/"no" responses. Then the composite score was dichotomized using the median (five) as a cutoff value so a score equal to or above the median value showed "good knowledge" and a score below the median value showed "poor knowledge".

Data was collected using a structured intervieweradministered questionnaire that was prepared based on the study objectives. The data collection tool was translated into the local language (Amharic). Four health officers with BSc degrees and two Msc graduates in public health were involved as data collectors and supervisors, respectively. To control data quality, a one day training was given to data collectors on the aim of the study and on how to select participants to collect the data as per the data collection tool by the principal investigator. The tool was pre-tested on $5 \%$ of the actual sample out of the study area, and the filled copies were checked by the supervisors daily.

\section{Data processing and analysis}

The data were entered into EPI info version 7.0 and transferred to SPSS version 25 for analysis. Chi-square test was done for all categorical independent variables to check the assumptions. Variance inflation factor (VIF) was used to check multi-collinearity. Descriptive statistics, like frequencies and percentages were used to describe the categorical independent variables. The binary logistic regression model was fitted as a primary method of analysis. Variables found to have $<0.2 p$-values in the bi-variate logistic regression analysis were entered in to the multivariable logistic regression model. Goodness of fit of the model was assessed by using the HosmerLemeshow goodness of fit test. Variables with less than $0.05 \mathrm{p}$ - values in the multivariable model were considered significantly associated with the dependent variable. Odds ratio (OR) with a 95\% confidence interval were computed to show the strength of associations.

\section{Results}

Socio demographic characteristics of the study participants A total of 364 participants were involved in the study with a response rate of $94 \%$. The majority of the participants, 282(77.5\%), 20-35 age groups with the minimum 
and maximum ages of 18 and 44 years, respectively. Nearly $85 \%$ (309) of the participants were married, while 352(96.7\%) and 257(70.6\%) were Amhara and Orthodox Christian, respectively. Of the participants, 160(44\%) were housewives and $87(23.9 \%)$ self-employed Besides, $113(31 \%)$ were with no formal education, and only $69(19 \%)$ were diploma or above graduates. More than half of the participants, 209(57.4\%), had ETB > 1000 monthly income. Over one-third, 131(36\%), of the participants had no travel expens to and from ANC facility (Table 1).

\section{Obstetric history of the study participants}

Of the total respondents, $128(35.2 \%)$ were primigravida and $167(70.8 \%)$ multiparous. Of these, $200(84.7 \%)$ reported that they had ANC experience during their previous pregnancy. Among respondents who had had an experience of ANC follow up 129(64.5\%) visited ANC clinic for the first time after 12 weeks of gestation in the previous pregnancy. Out of $31(13.1 \%)$ respondents who had history of abortion, 25 (80.64\%) were spontaneous.. Ninety-four (25.8\%) of the pregnancies were unintended. Of these, 64 came late for ANC for the current pregnancy. The majority of the respondents, 171 (72.5\%) faced no problems during their last pregnancies, and only $8(5 \%)$ had history of still births. Twenty-six (11\%) of respondents had history of CS delivery (Table 2).

\section{Timing of the current first ANC visit and knowledge towards ANC}

Of the total respondents, 173(47.5\%) had their first ANC initiation in 12 weeks of conception and 191(52.5\%) after 12 weeks (Fig. 2).

From the total respondents $247(67.9 \%)$ and 241 (66.2\%) perceived that ANC was highly important for them and for the fetus respectively. From the total study participants, 143(39.3\%) thought the appropriate time to book first ANC visit was before 12 weeks. From the total, 139(38.2\%) thought $\geq 8$ visits were required for ANC. One hundred ninety six (53.8\%) respondents perceived that mothers needed nutritional supplementation during pregnancy. Regarding the overall Knowledge of the mothers towards ANC 220(60.4\%) had a good knowledge (Table 3).

\section{Factors associated with late initiation of ANC}

In the bivariate analysis, factors like age, occupation, monthly income, knowledge level, health education, husband support and whether the pregnancy was planned or not were significantly associated with late initiation of ANC. However, in the multivariable analysis, only variables like occupational status, travel cost, knowledge about ANC and whether the pregnancy was planned or not were found to be the independent predictors of late
Table 1 Socio demographic characteristics of pregnant women who were attending ANC at Addis Zemen primary hospital, February -June $2018(n=364)$

\begin{tabular}{|c|c|c|c|}
\hline \multirow[t]{2}{*}{ Variable } & \multicolumn{2}{|c|}{ Time of ANC initiation } & \multirow{2}{*}{$\begin{array}{l}\text { Total n } \\
\text { (\%) }\end{array}$} \\
\hline & Early n (\%) & Late n (\%) & \\
\hline \multicolumn{4}{|l|}{ Age } \\
\hline$<20$ & $12(6.9)$ & $17(8.9)$ & $29(8)$ \\
\hline $20-35$ & $128(74)$ & $154(80.6)$ & $282(77.5)$ \\
\hline$>35$ & $33(19.1)$ & $20(10.5)$ & $53(14.6)$ \\
\hline \multicolumn{4}{|l|}{ Ethnicity } \\
\hline Amhara & $167(96.5)$ & $185(96.9)$ & $352(96.7)$ \\
\hline Other $^{a}$ & $6(3.5)$ & $6(3.1)$ & $12(3.3)$ \\
\hline \multicolumn{4}{|l|}{ Religion } \\
\hline Orthodox & $118(68.2)$ & $139(72.8)$ & $257(70.6)$ \\
\hline Muslim & $47(27.2)$ & $39(20.4)$ & 86 (23.6) \\
\hline Protestant & $7(4)$ & $13(6.8)$ & $20(5.5)$ \\
\hline Catholic & $1(0.6)$ & $0(0)$ & $1(0.3)$ \\
\hline \multicolumn{4}{|l|}{ Marital status } \\
\hline Single & $15(8.7)$ & $20(10.5)$ & $35(9.6)$ \\
\hline Married & $152(87.9)$ & $157(82.2)$ & 309 (84.9) \\
\hline Divorced/widowed & $6(3.5)$ & $14(7.3)$ & $20(5.5)$ \\
\hline \multicolumn{4}{|l|}{ Educational level } \\
\hline No formal education & $47(27.2)$ & 66 (34.6) & $113(31)$ \\
\hline Primary (1-8) & $44(25.4)$ & $67(35.1)$ & $111(30.5)$ \\
\hline Secondary and preparatory & $32(18.5)$ & $39(20.4)$ & $71(19.5)$ \\
\hline Diploma and above & $50(28.9)$ & $19(9.9)$ & $69(19)$ \\
\hline \multicolumn{4}{|l|}{ Occupation } \\
\hline Government employed & $47(27.2)$ & $18(9.4)$ & $65(17.9)$ \\
\hline Self employed & $37(21.4)$ & $50(26.2)$ & 87 (23.9) \\
\hline House wife & 69 (39.9) & 91 (47.6) & $160(44)$ \\
\hline Other ${ }^{\mathrm{b}}$ & $20(11.6)$ & $32(16.8)$ & $52(14.3)$ \\
\hline \multicolumn{4}{|l|}{ Income } \\
\hline$<400$ ETB & $19(11)$ & $15(7.9)$ & $34(9.3)$ \\
\hline 400-1000 ETB & $44(25.4)$ & $77(40.3)$ & $121(33.2)$ \\
\hline$>1000$ ETB & $110(63.6)$ & $99(51.8)$ & 209 (57.4) \\
\hline \multicolumn{4}{|l|}{ Transport cost } \\
\hline$<3 \mathrm{ETB}$ & $41(23.7)$ & $28(14.7)$ & $69(19)$ \\
\hline 3-9 ETB & $35(20.2)$ & $33(17.3)$ & $68(18.7)$ \\
\hline$>9 \mathrm{ETB}$ & $43(24.9)$ & $53(27.7)$ & $96(26.4)$ \\
\hline Did not pay & $54(31.2)$ & 77 (40.3) & $131(36)$ \\
\hline
\end{tabular}

Other ${ }^{\mathrm{a}}$ - Oromo/Tigre/ Gurage, other ${ }^{\mathrm{b}}$-Daily laborer/ NGO/ farmer/ student. ETB: Ethiopian Birr

booking for ANC. The odds of booking ANC late was 2.85 times higher among housewives compared to mothers who were government employed keeping other variables constant ( $\mathrm{AOR}=2.85,95 \% \mathrm{CI}: 1.36,5.96)$. The odds of booking ANC late was 2.38 times higher among 
Table 2 Obstetric history of pregnant women who were attending ANCat Addis Zemen primary hospital, February -June $2018(n=364)$

\begin{tabular}{|c|c|c|c|}
\hline \multirow[t]{2}{*}{ Variable } & \multicolumn{2}{|c|}{ Time of ANC initiation } & \multirow[t]{2}{*}{ Total n (\%) } \\
\hline & Early n (\%) & Late n (\%) & \\
\hline \multicolumn{4}{|c|}{ Gravidity $(n=364)$} \\
\hline Primigravida & $55(31.8)$ & $73(38.2)$ & $128(35.2)$ \\
\hline Multigravida & $118(68.2)$ & $118(61.8)$ & $236(64.8)$ \\
\hline \multicolumn{4}{|l|}{ Parity $(n=236)$} \\
\hline Primiparous & $37(31.4)$ & $32(27.1)$ & $69(29.2)$ \\
\hline Multiparus & $81(68.6)$ & $86(72.9)$ & $167(70.8)$ \\
\hline \multicolumn{4}{|c|}{ Abortion history $(n=236)$} \\
\hline Yes & $17(14.4)$ & $14(11.9)$ & $31(13.1)$ \\
\hline No & $101(85.6)$ & $104(88.1)$ & $205(86.9)$ \\
\hline \multicolumn{4}{|c|}{ Planned pregnancy $(n=364)$} \\
\hline Yes & $143(82.7)$ & $127(66.5)$ & $270(74.2)$ \\
\hline No & $30(17.3)$ & $64(33.5)$ & $94(25.8)$ \\
\hline \multicolumn{4}{|c|}{ Alive child $(n=234)$} \\
\hline 0 & $1(0.9)$ & $2(1.7)$ & $3(1.3)$ \\
\hline 1 & 37 (31.6) & $32(27.4)$ & $69(29.5)$ \\
\hline $2-4$ & $69(59)$ & $78(66.7)$ & $147(62.8)$ \\
\hline$>4$ & $10(8.5)$ & $5(4.3)$ & $15(6.4)$ \\
\hline \multicolumn{4}{|c|}{ Child death $(n=222)$} \\
\hline Yes & $2(1.8)$ & $4(3.7)$ & $6(2.8)$ \\
\hline No & $112(98.2)$ & $104(96.3)$ & $216(97.3)$ \\
\hline \multicolumn{4}{|c|}{ Still birth $(n=160)$} \\
\hline Yes & $2(2.9)$ & $6(6.7)$ & $8(5)$ \\
\hline No & $68(97.1)$ & $84(93.3)$ & $152(95)$ \\
\hline \multicolumn{4}{|c|}{ Problem in the last pregnancy $(n=236)$} \\
\hline Yes & $36(30.5)$ & $29(24.6)$ & $65(27.5)$ \\
\hline No & $82(69.5)$ & $89(75.4)$ & $171(72.5)$ \\
\hline \multicolumn{4}{|c|}{ CS history $(n=236)$} \\
\hline Yes & $13(11)$ & $13(11)$ & $26(11)$ \\
\hline No & $105(89)$ & $105(89)$ & $210(89)$ \\
\hline \multicolumn{4}{|c|}{ History of ANC $(n=236)$} \\
\hline Yes & $102(86.4)$ & $98(83.1)$ & $200(84.7)$ \\
\hline No & 16 (13.6) & $20(16.9)$ & $36(15.3)$ \\
\hline \multicolumn{4}{|c|}{ ANC initiation time for the previous pregnancy $(n=200)$} \\
\hline$\leq 12$ weeks & $47(46.1)$ & $24(24.5)$ & $71(35.5)$ \\
\hline$>12$ weeks & 55 (53.9) & $74(75.5)$ & $129(64.5)$ \\
\hline
\end{tabular}

self-employed mothers compared to government employed keeping other variables constant $(\mathrm{AOR}=2.38$, 95\% CI: 1.12, 5.04). The odds of booking ANC late increased by $72 \%$ among mothers who paid for transport to go to ANC service compared to those who did not pay keeping other variables constant $(\mathrm{AOR}=1.72,95 \%$ CI: 1.05, 2.81). The odds of being late for booking ANC was nearly three times higher among mothers who had poor knowledge of ANC as compared to mothers with good knowledge keeping other variables constant $(\mathrm{AOR}=2.98,95 \% \mathrm{CI}: 1.78,5.01)$. The odds of being late for booking ANC was 2.31 times higher among mothers who had unintended pregnancy compared to mothers with planned pregnancy keeping other variables constant $(\mathrm{AOR}=2.31,95 \% \mathrm{CI}: 1.28,4.16)($ Table 4$)$.

\section{Discussion}

This study mainly assessed the prevalence of late ANC initiation and associated factors among pregnant mother who attended ANC at Addis Zemen primary hospital. Different studies reported different risk factors for late initiation of ANC; our study assessed the socio demographic, obstetric, enabling, and need factors. As a result, factors like housewife status and self-employment, payment for travel, poor knowledge about ANC, and unintended pregnancy were found be significantly associated with late initiation of ANC.

World Health Organization recommends that pregnant mothers, especially those who are living in developing countries should start ANC in the first three months of pregnancy [12]. In our study however more than half of the respondents (52.5\%) initiated ANC after the recommended time. This result is consistent with those other studies conducted in Adigrat (Ethiopia) [23], South Africa [10], Myanmar [29] and Gondar (Ethiopia) [30]. In this study he prevalence of booking ANC late was higher than those of studies done in Addis Ababa and Debre Markos, Ethiopia which showed 42 and 33.4\% respectively [31, 32]. This could be due to the fact that, Addis Ababa is the capital of the country and the community might have better awareness and access to health service than people in other parts of the country. Another reason could be the classification of the outcomes because the study in Debre Markos classified mothers as late for booking ANC if they come after 16 weeks of gestation, while our study classified a mother as being late if she came after 12 weeks.. On the other hand, our finding was lower than the result of other studies done in Ambo,Ethiopia (86.8\%) [24] Kembata Tembaro zone, Ethiopia (68.6\%) [27], Gondar,Ethiopia (65\%) [11], Southern Ethiopia (78.3\%) [25], Tanzania (70.4\%) [17], Zambia (72\%) [22], Nigeria (82.6\%) [33], East Wollega, Ethiopia (81.5\%) [26], Gedio Zone,Ethiopia (64.6\%) [19] and meta-analysis that used a polled data from studies done in Ethiopia (64\%) [20]. This could be explained by the socio-cultural differences among the study populations. Another reason could be time differences between the studies because currently there is a better improvement in awareness about ANC and there is also good access to the health facilities than the past times in Ethiopia [34]. 


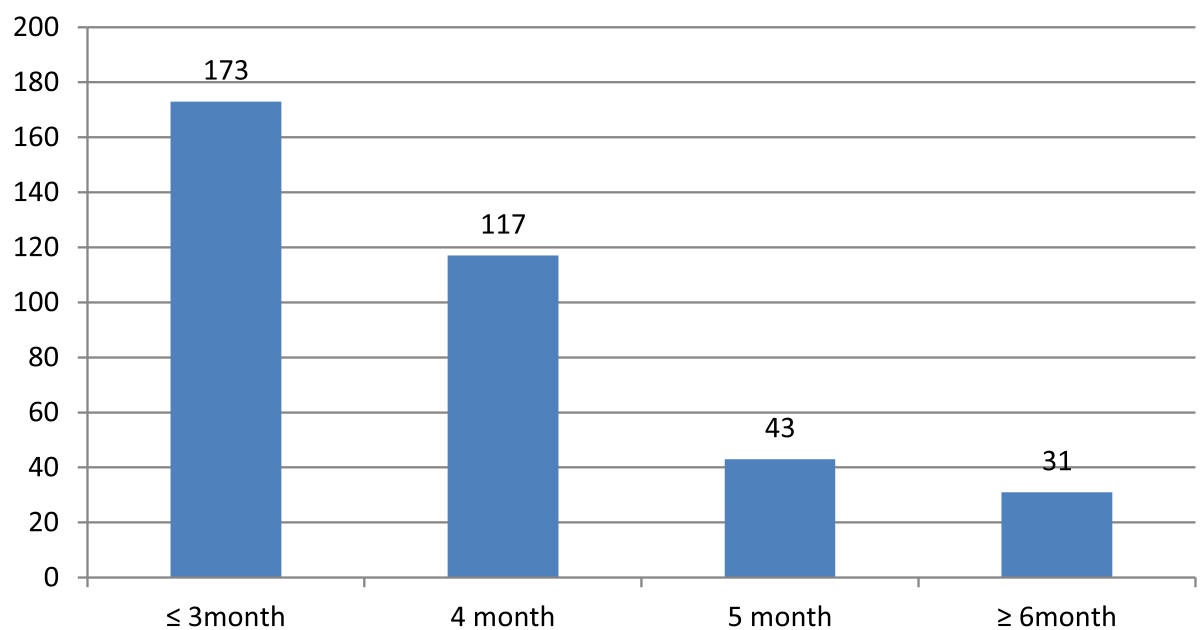

Fig. 2 Timing of first ANC visit for pregnant mothers who were attending ANC in Addis Zemen primary hospital, February-June 2018

In this study, housewives and self-employed mothers had increased odds of booking ANC late than government employed mothers. This result is consistent with that of a study done in Tanzania [17] and showed that housewives were at increased odds of booking ANC late. The reason could be explained by the workload housewives shoulder in the house and the lack of time to go to health facilities. Another reason could be poor educational status because the majority did not have formal education. The possible reason for self-employed mothers to be late for ANC might be lack of time. In addition, mothers might be busy making money for the basic needs of their families. Therefore, even if they knew the appropriate time for the visit, they might be late because of their busy days. According to our study, the odds of booking ANC late increased by $72 \%$ among mothers who paid for transport to get to ANC service compared to those who did not pay. This result is consistent with a study done in Addis Ababa [18]. The possible reason could be that mothers, especially from rural areas are expected to travel long distance to reach health facilities; so they may need wait until they get money for transport.

In our study, $39.6 \%$ of the mothers had poor knowledge about ANC which was associated with 2.98 times increased odds of booking ANC late. This result is in line with those of studies conducted in Ethiopia [19, 20, 25] and Zambia [22]. This could be explained by the fact that mothers with poor knowledge may not have awareness about the correct time for booking and may not know the importance of ANC both for the mother and the fetus.

According to our study, mothers who had unintended pregnancy had 2.31 times increased odds of booking ANC late compared to mothers with planned pregnancy. This result is consistent with those of other studies done in different parts of Ethiopia [18, 21, 23, 27, 32, 35], Zambia [22] and South Africa [10]. The possible reason might be that mothers with unintended pregnancy may miss a support from their partners or families which may decrease their good health seeking behavior [36]. Another reason could be that women with unplanned pregnancies may initially attempt to deny their pregnancies to themselves and to

Table 3 Knowledge towards ANC among pregnant mothers who were attending ANC at Addis Zemen primary hospital, FebruaryJune $2018(n=364)$

\begin{tabular}{|c|c|c|}
\hline Questions & Yes & No \\
\hline Do you think ANC is importance for maternal health? & $247(67.9)$ & $117(32.1 \%$ \\
\hline Do you think ANC is important for the fetus? & $241(66.2 \%)$ & $123(33.8 \%)$ \\
\hline Do you think the appropriate time to begin ANC after conception is $<12$ weeks? & $143(39.3 \%)$ & $221(60.7 \%)$ \\
\hline Do you think a woman needs to go for ANC $>8$ times? & $139(38.2 \%)$ & $225(61.8 \%)$ \\
\hline Do you think a pregnant mother need to initiate ANC early only if she had complication in her previous pregnancy? & $237(65.1 \%)$ & $127(34.9 \%)$ \\
\hline Do you think pregnant mother needs supplementation during her pregnancy? & $196(53.8 \%)$ & $168(46.2 \%)$ \\
\hline Do you know maternal conditions risk for the fetus & $137(37.6 \%)$ & $227(62.4 \%)$ \\
\hline Dou you think appropriate ANC follow up can prevent disease transmission from mother to child? & $308(84.6 \%)$ & $56(15.4 \%)$ \\
\hline Dou you think appropriate ANC follow up can prevent erythroblastosis fetalis? & $29(8 \%)$ & 335 (92\%) \\
\hline
\end{tabular}


Table 4 Multivariable logistic regression of predictors to late ANC initiations among pregnant women at Addis Zemen primary hospital, February -June $2018(n=364)$

\begin{tabular}{llll}
\hline Variable & $\begin{array}{l}\text { Crud OR } \\
(95 \% \mathrm{Cl})\end{array}$ & $\begin{array}{l}\text { Adjusted HR } \\
(95 \% \mathrm{Cl})\end{array}$ & $P$-value \\
& & &
\end{tabular}

Age (years)

$>35$

$<20$

$20-35$

Marital status

Married

Other $^{\mathrm{a}}$

Educational status

Literate

No formal education

$1.4(0.9,2.2)$

$0.89(0.48,1.62)$

0.696

Occupation

Government employed
Housewife
Self employed
Other $^{\text {b }}$

Income/month

$>1000$ ETB

$<400$ ETB

400-1000 ETB

Transport cost

Don't pay
Pay
Gravidity
Multigravida
Primigravida
Knowledge level
Good
Poor

Planned pregnancy

Yes

No

Health education

Yes

No

Advice about ANC

Yes

No

Husband support

Yes

No

$2.3(0.9,5.9)$

$1.2(1.1,3.6)$

$2.0(0.95,4.29)$

0.426

0.066

$1.6(0.9,2.8) \quad 0.93(0.46,1.86)$

0.822

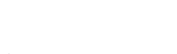

$3.4(1.8,6.4)$

$3.5(1.8,7.0)$

$2.85(1.36,5.96)$

$2.38(1.12,5.04)$

$4.2(1.9,9.1)$

$2.13(0.87,5.19)$

0.005

0.024

0.096

163

$0.9(0.4,1.8) \quad 0.53(0.23,1.30)$

$1.9(1.4,3.1) \quad 1.51(0.87,2.60)$

0.142

0.033

$1.5(0.9,2.3) \quad 1.72(1.05,2.81)$

1

$1.3(0.8,2.0)$

$0.87(0.50,1.52)$

0.626

$1 \quad 1$

$3.6(2.3,5.6) \quad 2.98(1.78,5.01)$

0.000

$\begin{array}{ll}1 & 1 \\ 2.4(1.4,4) & 2.31(1.28,4.16)\end{array}$

0.005

11

$2.1(1.3,3.2)$

$1.67(0.98,2.85)$

0.059

1

$1.4(0.9,2.2) \quad 0.87(0.50,1.50)$

0.609

Other $^{\mathrm{a}}$-single/divorced/widowed, Other ${ }^{\mathrm{b}}$-daily laborer/NGO/farmer/student, ANC: anti natal care, ETB: Ethiopian Birr

The boldface indicates significant associations with $p$-value $<0.05$ conceal them from others. As a result, such women become less motivated to seek ANC early compared to women with planned pregnancies. Furthermore, unplanned pregnancies are also related to socio-cultural determinants of health-seeking behaviors, sexual violence, and barriers to access which may be associated with late initiations [10].

The limitation of this study was using only governmental health facilities because some pregnant women may visit private health facilities so these mothers were not included in our study. Besides, studies use different cutoff points to categorize women as late or otherwise, making it difficult to compare our findings with other studies.

\section{Conclusion}

Late booking for ANC was high in Ethiopia. According to our study the factors for lateness were being housewife and self-employment, poor knowledge about ANC, paying for travel to go for ANC, and unintended pregnancy. The district and zonal health offices should work on creating awareness about the benefits of early initiation of ANC both for the mother and the fetus. On the other hand, awareness should be created about family planning utilization to prevent untended pregnancies. It is also better to make the service closer to mothers who need to travel long distances. Moreover, the government also needs to meet the WHO-recommendation for the accessibility of health facilities to pregnant women.

\section{Abbreviations}

ANC: Antenatal Care; AOR: Adjusted odds ratio; ART: Anti retroviral treatment; BSC: Bachelor of sciences; CS: Ceserian section; EDHS: Ethiopian demographic health survey; ETB: Ethiopian Birr; HIV: Human immune deficiency virus; KM: Kilo meters; OR: Odds ratio; PMTCT: Prevent mother-to-child transmission; SPSS: Statistical package for social science; TT: Tetanus toxoid; VIF: Variance inflation factor; WHO: World Health Organization

\section{Acknowledgments}

We would like to express our deepest thanks to University of Gondar College of Medicine and Health Sciences and Health Officer Department, for facilitating the research work. We also want to thank all pregnant women who participated in this study for their contribution.

\section{Authors' contributions}

All authors equally contribute for conception and design, acquisition of data, or analysis and interpretation of data. HF, MM and AT critically revise the manuscript. All authors read and approved the final version of the manuscript.

\section{Funding}

Not applicable

\section{Availability of data and materials}

The data upon which the result based could be accessed a reasonable request.

\section{Ethics approval and consent to participate}

This work has been approved by the ethical review committee of University of Gondar, Collage of Medicine and Health Science. Formal Permission was obtained from Addis Zemen Primary hospital. Verbal Informed consent was also obtained from all participants after explaining the purpose of the study. Participants were clearly informed that they have full right to refuse or withdraw from the study. Privacy of the patients was maintained, Names were not included, and questionnaires kept locked. 


\section{Consent for publication}

Not applicable

\section{Competing interests}

The authors declare that they have no competing interests.

Received: 21 March 2019 Accepted: 23 May 2019

Published online: 31 May 2019

\section{References}

1. Kassebaum NJ, Arora M, Barber RM, Bhutta ZA, Brown J, Carter A, et al. Global, regional, and national disability-adjusted life-years (DALYs) for 315 diseases and injuries and healthy life expectancy (HALE), 1990-2015: a systematic analysis for the Global Burden of Disease Study 2015. Lancet. 2016:388(10053):1603-58

2. World Health Organization. Trends in maternal mortality: 1990-2015: estimates from WHO, UNICEF, UNFPA, World Bank Group and the United Nations Population division: executive summary. World Health Organization, 2015.

3. Mahler $\mathrm{H}$. The safe motherhood initiative: a call to action. Lancet (London, England). 1987;1(8534):668

4. World Health Organization. Global health observatory (GHO) data. 2015

5. Alkema L, Chou D, Hogan D, Zhang S, Moller A-B, Gemmill A, et al. Global, regional, and national levels and trends in maternal mortality between 1990 and 2015, with scenario-based projections to 2030: a systematic analysis by the UN maternal mortality estimation inter-agency group. Lancet. 2016; 387(10017):462-74

6. Lawn JE, Lee AC, Kinney M, Sibley L, Carlo WA, Paul VK, et al. Two million intrapartum-related stillbirths and neonatal deaths: where, why, and what can be done? Int J Gynecol Obstet. 2009;107(Supplement):S5-S19.

7. Organization $\mathrm{WH}$. WHO recommendations on antenatal care for a positive pregnancy experience. In: World Health Organization; 2016.

8. Moller A-B, Petzold M, Chou D, Say L. Early antenatal care visit: a systematic analysis of regional and global levels and trends of coverage from 1990 to 2013. Lancet Glob Health. 2017;5(10):e977-e83.

9. Allen D, Ammann A, Bailey H, Allen D, Ammann A, Bailey H, et al. Revised Recommendation for HIV Screening of Pregnant Women. Atlanta, Georgia: Prenatal Counseling and Guidelines for Consultation; 2001.

10. Ebonwu J, Mumbauer A, Uys M, Wainberg ML, Medina-Marino A. Determinants of late antenatal care presentation in rural and peri-urban communities in South Africa: a cross-sectional study. PLoS One. 2018;13(3):e0191903.

11. Gudayu TW. Proportion and factors associated with late antenatal care booking among pregnant mothers in Gondar town, north West Ethiopia. Afr J Reprod Health. 2015;19(2):93-9.

12. World Health Organization. WHO antenatal care randomized trial: manual for the implementation of the new model. 2002.

13. Orvos H, Hoffmann I, Frank I, Katona M, Pál A, Kovács L. The perinatal outcome of pregnancy without prenatal care: a retrospective study in Szeged, Hungary. Eur J Obstet Gynecol Reprod Biol. 2002;100(2):171-3.

14. Tuladhar $\mathrm{H}$, Dhakal $\mathrm{N}$. Impact of antenatal care on maternal and perinatal utcome: a study at Nepal medical college teaching hospital. Nepal J Obstet Gynaecol. 2011;6(2):37-43.

15. Kisuule I, Kaye DK, Najjuka F, Ssematimba SK, Arinda A, Nakitende G, et al. Timing and reasons for coming late for the first antenatal care visit by pregnant women at Mulago hospital, Kampala Uganda. BMC Pregnancy Childbirth. 2013;13(1):121

16. Medhanyie A, Spigt M, Kifle Y, Schaay N, Sanders D, Blanco R, et al. The role of health extension workers in improving utilization of maternal health services in rural areas in Ethiopia: a cross sectional study. BMC Health Serv Res. 2012;12(1):352

17. Njiku F, Wella H, Sariah A, Protas J. Prevalence and factors associated with late antenatal care visit among pregnant women in Lushoto, Tanzania. Tanzania J Health Res. 2017;19(3)

18. Gebrekidan K, Worku A. Factors associated with late ANC initiation among pregnant women in select public health centers of Addis Ababa, Ethiopia: unmatched case-control study design. Pragmat Obs Res. 2017:8:223.

19. Abuka T, Alemu A, Birhanu B. Assessment of timing of first antenatal care booking and associated factors among pregnant women who attend antenatal Care at Health Facilities in Dilla town, Gedeo zone, southern nations, nationalities and peoples region, Ethiopia, 2014. J Preg Child Health. 2016:3(258):2.
20. Tesfaye G, Loxton D, Chojenta C, Semahegn A, Smith R. Delayed initiation of antenatal care and associated factors in Ethiopia: a systematic review and meta-analysis. Reprod Health. 2017;14(1):150.

21. Gebremeskel F, Dibaba Y, Admassu B. Timing of first antenatal care attendance and associated factors among pregnant women in Arba Minch town and Arba Minch District, Gamo Gofa zone, South Ethiopia. J Environ Public Health. 2015;2015.

22. Banda I, Michelo C, Hazemba A. Factors associated with late antenatal care attendance in selected rural and urban communities of the Copperbelt province of Zambia. Med J Zamb. 2012;39(3):29-36.

23. Lerebo W, Kidanu A, Tsadik M. Magnitude and associated factors of late booking for antenatal Care in Public Health Centers; 2015.

24. Damme TG. Factors associated with late antenatal care attendance among pregnant women attending health facilities of ambo town, west Shoa zone, Oromia region, Central Ethiopia. Int J Med Pharm Sci. 2015:1(2):56-60.

25. Geta MB, Yallew WW. Early initiation of antenatal care and factors associated with early antenatal care initiation at health facilities in southern Ethiopia. Adv Public Health. 2017;2017.

26. Ejeta E, Dabsu R, Zewdie O, Merdassa E. Factors determining late antenatal care booking and the content of care among pregnant mother attending antenatal care services in east Wollega administrative zone, West Ethiopia. Pan Afr Med J. 2017;27(1).

27. Tekelab T, Berhanu B. Factors associated with late initiation of antenatal care among pregnant women attending antenatal Clinic at Public Health Centers in Kembata Tembaro zone, southern Ethiopia. Sci Technol Arts Res J. 2014:3(1):108-15.

28. CSA. Population and Housing Census Report at National Level Addis Ababa E.

29. Aung TZ, Oo WM, Khaing W, Lwin N, Dar HT. Late initiation of antenatal care and its determinants: a hospital based cross-sectional study. Int J Community Med Public Health. 2017;3(4):900-5.

30. Belayneh T, Adefris M, Andargie G. Previous early antenatal service utilization improves timely booking: cross-sectional study at university of Gondar hospital, Northwest Ethiopia. J Pregnancy. 2014;2014

31. Gulema H, Berhane Y. Timing of first antenatal care visit and its associated factors among pregnant women attending public health facilities in Addis Ababa, Ethiopia. Ethiopian J Health Sci. 2017;27(2):139-46.

32. Ewunetie AA, Munea AM, Meselu BT, Simeneh MM, Meteku BT. DELAY on first antenatal care visit and its associated factors among pregnant women in public health facilities of Debre Markos town, north West Ethiopia. BMC Pregnancy Childbirth. 2018;18(1):173.

33. Adekanle D, Isawumi A. Late antenatal care booking and its predictors among pregnant women in South Western Nigeria. Online J Health Allied Sci. 2008;7(1).

34. Health FDRoEMo. Health Sector Development Program IV, 2010/11-2014/ 15. Ministry of Health Addis Ababa; 2010.

35. Tariku A, Melkamu Y, Kebede Z. Previous utilization of service does not improve timely booking in antenatal care: cross sectional study on timing of antenatal care booking at public health facilities in Addis Ababa. Ethiop J Health Dev. 2010;(3):24

36. Exavery A, Kanté AM, Hingora A, Mbaruku G, Pemba S, Phillips JF. How mistimed and unwanted pregnancies affect timing of antenatal care initiation in three districts in Tanzania. BMC Pregnancy Childbirth. 2013;13(1):35.

\section{Publisher's Note}

Springer Nature remains neutral with regard to jurisdictional claims in published maps and institutional affiliations.

Ready to submit your research? Choose BMC and benefit from:

- fast, convenient online submission

- thorough peer review by experienced researchers in your field

- rapid publication on acceptance

- support for research data, including large and complex data types

- gold Open Access which fosters wider collaboration and increased citations

- maximum visibility for your research: over $100 \mathrm{M}$ website views per year

At BMC, research is always in progress.

Learn more biomedcentral.com/submission 